\title{
Anti-rollover Control System Design of Articulated Off-road Vehicles
}

\author{
Shuai Wang ${ }^{1}$, Yuxin Zhang ${ }^{2}$, Chao Chen ${ }^{1}$, and Huikai Liu ${ }^{1}$ \\ ${ }^{1}$ College of Mechanical Science and Engineering, Jilin University, 130022 Changchun, China \\ ${ }^{2}$ State Key Laboratory of Automotive Simulation and Control, Jilin University, 130022 Changchun, China
}

\begin{abstract}
This paper designs an anti-rollover control system to improve articulated off-road vehicle rollover safety. This controller consists two level control which target to two different instability stages: 1) the active swing bridge adjustment control algorithm for the first stage instability; and 2) the active braking control algorithm for the second stage instability. The first level control is based on fuzzy PID control and second is based on switch control, they work together to prevent the articulated wheel loader from rollover accident. Multi-body dynamics model of a ZL50 articulated wheel loader is built by commercial software RecurDyn, and the MBD model and controller model were co-simulated under the same solver in RecurDyn/CoLink. The co-simulation results show that, during the high speed steering rollover process, these two level controller work efficiently to reduce the roll angle and improve the vehicle rollover stability.
\end{abstract}

\section{Introduction}

Articulated steering system is widely used in off-road and engineering vehicles due to its several advantages, such as small steering radius, good manoeuvring characteristics, simple structure, and low power consumption.

While the articulated steering vehicles became popular and widely used, the security problems are becoming increasingly prominent [1]. Compared to the vehicles with overall frame, the articulated engineering or off-road vehicles have a special body structure, which usually leads to an additional degree of freedom, and reduces vehicle lateral stiffness. Therefore, this kind of vehicles are easier to be caused rollover accidents which lead to casualties and economic loss [2].

In order to ensure the driver's life safety, international standard ISO3471 requirements that the engineering vehicles must be installed rollover protection structure (ROPS) which can protect the driver in rollover accidents passively [3], however this approach does not solve the root of the problem.

At present, the safety research about articulated offroad vehicles are mainly focused on passive rollover safety, rollover mechanism, rollover and steering stability analysis, etc. [4]. There are only a few researches on the active anti-rollover control system [5-7] and most of them are focused on commercial vehicles and SUVs.

D. J. M. Sampson et al developed an active antirollover control system for articulated commercial vehicles, and introduced the hardware structure and software development of the control system in detail [8]. Through controlling the active anti-roll bar by a hydraulic actuator, it can adjust the traction semi-trailer roll motion.
The simulation results have shown that this control system can significantly improve traction semi-trailer stability, and reduce rollover accident probability.

P. Gaspar developed a reconfigurable control system for heavy vehicles, it combined active anti-roll bar control and active braking control [9]. At the same time, the optimal anti-rollover control strategy considered several roll dynamics parameters, such as roll angle, roll angular velocity, lateral angular velocity and lateral acceleration.

M. M. Islam built a 5 DOF single articulated trailer heavy vehicle model and a 7 DOF multi-trailer heavy vehicle model, and simulated them using TruckSim [10]. By combining trailer active steering control, active antiroll bar control, and differential braking control, this control system can effectively improve low-speed maneuverability and high-speed cornering lateral stability. N. Daher investigated a yaw stability control system for articulated frame steering off-highway vehicles via novel steer-by-wire technology that they have recently developed [11], this work explores whether the new technology can also deliver increased safety as well, by providing active safety functions.

Y. X. Zhang established wheel loader dynamic rollover model and the rollover warning strategy model by MATLAB/Simulink [7]. Through the simulation results analysis, the effectiveness of warning strategy under high-speed transport and sharp steering was verified. What's more, a physical prototype test was performed using the remote control loader model vehicle.

In this paper, a fuzzy PID controller is designed to improve articulated off-road vehicle rollover safety, especially the research object is an articulated wheel loader. Section 2 introduces the design process of the 
active-anti rollover controller. Section 3 describes the multi-body dynamics modeling of the wheel loader. Section 4 sets up the co-simulation. Simulation results are shown in section 5. Finally, the conclusions are given in section 6 .

\section{Controller Design}

The designed active anti-rollover control system is divided into two levels, they are used in different stages of the rollover process: 1) for the first stage instability of the loader, the active swing bridge adjustment control algorithm will be activated; and 2) for the second stage instability of the loader, the active braking control algorithm will be activated.

Fuzzy control has good noise suppression ability and good robustness, which is suitable for nonlinear systems. However, the inherent weakness of fuzzy control is that the steady state performance is poor, and it is easy to produce the limit oscillations near the equilibrium point.
The traditional PID control has many advantages, but its fixed set of control parameters cannot adapt to environmental interference.

In order to improve the control effect, this paper developed a fuzzy PID controller, which takes advantages from both fuzzy control and traditional PID control. Based on fuzzy control, the fuzzy PID controller can tune the three key parameters $K_{P}, K_{I}$ and $K_{D}$ of the PID control online using fuzzy logic inference $[12,13]$.

As shown in Figure 1, a two dimensional fuzzy controller is used in this paper. The inputs are deviation $e$ and its rate $e c$, and the outputs are the three key parameters of PID controller, $K_{P}, K_{I}$ and $K_{D}$. In practice, in order to accelerate the control system response speed, the increment of these three parameters $\Delta K_{P}, \Delta K_{I}$ and $\Delta$ $K_{D}$ are used instead of directly tuning parameters $K_{P}, K_{I}$ and $K_{D}$. Figure 1 shows the structure diagram of the fuzzy PID controller.

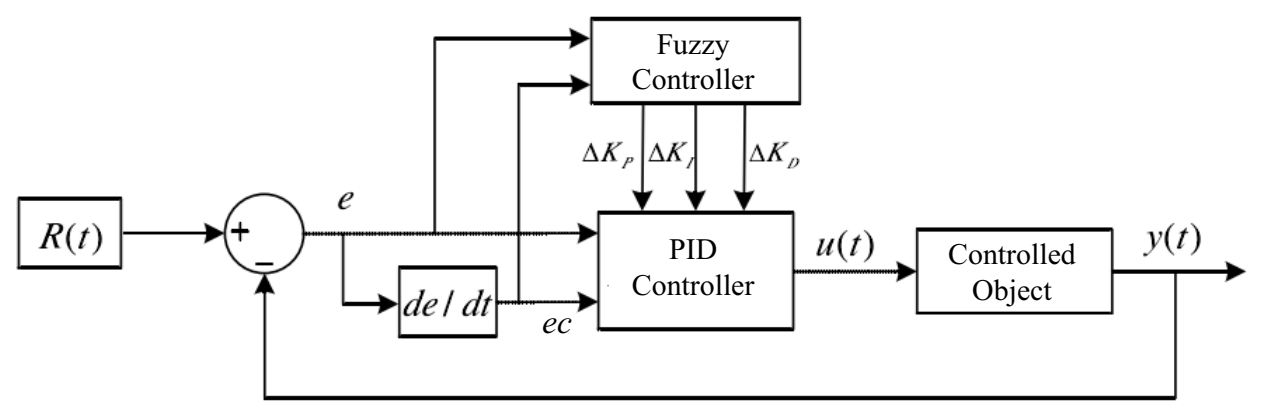

Figure 1. Structure diagram of the fuzzy PID controller.

For the PID controller part, its inputs $K_{P}, K_{I}$ and $K_{D}$ are calculated from the output of fuzzy controller $\Delta K_{P}, \Delta$ $K_{I}$ and $\Delta K_{D}$ and the previous system initial value $K_{P 0}, K_{I 0}$ and $K_{D 0}$, and then the control variable $u(t)$ is generated and acted on the controlled object. The calculation formula of $K_{P}, K_{I}$ and $K_{D}$ are as follows:

$$
\begin{aligned}
& K_{P}=K_{P 0}+\Delta K_{P} \\
& K_{I}=K_{I 0}+\Delta K_{I} \\
& K_{D}=K_{D 0}+\Delta K_{D}
\end{aligned}
$$

For the active swing bridge control, the feedback signal $y(t)$ is roll angle $\varphi(t)$, while the given input is a fixed roll angle. Therefore, the roll angle deviation $e$ of the fuzzy control is:

$$
e=R(T)-\varphi(t)=-\varphi(t)
$$

The change rate $e c$ of the roll angle deviation is:

$$
e c=d e / d t=\frac{d(0-\varphi(t))}{d t}=-\omega(t)
$$

The outputs of the fuzzy control are the correction parameters of the PID control $\Delta k_{p}, \Delta k_{i}$ and $\Delta k_{d}$. The basic domains of $e, e c, \Delta k_{p}, \Delta k_{i}$ and $\Delta k_{d}$ are $\left[-e_{\max }, e_{\max }\right]$, $\left[-e c_{\text {max }}, e c_{\text {max }}\right] \quad, \quad\left[-\Delta k_{\text {pmax }}, \Delta k_{\text {pmax }}\right]$, $\left[-\Delta k_{\text {imax }}, \Delta k_{\text {imax }}\right]$, and $\left[-\Delta k_{\text {dmax }}, \Delta k_{\text {dmax }}\right]$, respectively. The linguistic variables of inputs and outputs are $E, E C, K_{P}, K_{I}$ and $K_{D}$, respectively and their fuzzy discrete domains are $\left[-n_{1}, n_{1}\right],\left[-n_{2}, n_{2}\right],\left[-m_{1}, m_{1}\right],\left[-m_{2}, m_{2}\right]$, and $\left[-m_{3}, m_{3}\right]$. The input quantization factors are:

$$
\begin{aligned}
& K_{e}=n_{1} / e_{\max } \\
& K_{e c}=n_{2} / e c_{\max }
\end{aligned}
$$

The comparative factors of output variables are:

$$
\begin{aligned}
& K_{u 1}=\Delta k_{\text {pmax }} / m_{1} \\
& K_{u 2}=\Delta k_{\text {imax }} / m_{2} \\
& K_{u 3}=\Delta k_{\text {dmax }} / m_{3}
\end{aligned}
$$

The fuzzy subsets of the input and output variables are all seven: NB (Large negative), NM (Medium negative), NS (Small negative), ZO (zero), PS (Small positive), PM (Medium positive), PB (Large positive). The membership function of fuzzy subsets is:

$$
\mu(x)= \begin{cases}\frac{x-a}{b-a}, & a<x<b \\ \frac{x-c}{b-c}, & b<x<c\end{cases}
$$

where $a, b$, and $c$ are slopes of membership functions.

Based on Mamdani's reasoning method, the fuzzy control rules of $\Delta K_{P}, \Delta K_{I}$ and $\Delta K_{D}$ are shown in Table 1 to Table 3 .

In this paper, weighted average method is used to realize the process of ambiguity resolution:

$$
\Delta K_{P}=\frac{\sum_{i=1}^{49} \mu_{P i}\left(\Delta K_{P}\right) \times \Delta K_{P_{i}}}{\sum_{i=1}^{49} \mu_{P i}\left(\Delta K_{P}\right)}
$$


where, $\mu_{P i}\left(\Delta K_{P}\right)=\mu_{P i}(E) \times \mu_{P i}(E C)$. The processes of ambiguity resolution for $\Delta K_{I}$ and $\Delta K_{D}$ are similar.

Table 1. Fuzzy control rules of $\Delta K_{P}$.

\begin{tabular}{c|ccccccc}
\hline EC & $N B$ & $N M$ & $N S$ & $Z O$ & $P S$ & $P M$ & $P B$ \\
\hline$N B$ & $P B$ & $P B$ & $P M$ & $P M$ & $P S$ & $Z O$ & $Z O$ \\
$N M$ & $P B$ & $P M$ & $P M$ & $P S$ & $P S$ & $Z O$ & $N S$ \\
$N S$ & $P M$ & $P M$ & $P S$ & $P S$ & $Z O$ & $N S$ & $N S$ \\
$Z O$ & $P M$ & $P M$ & $P S$ & $Z O$ & $N S$ & $N M$ & $N M$ \\
$P S$ & $P S$ & $P S$ & $Z O$ & $N S$ & $N S$ & $N M$ & $N M$ \\
$P M$ & $P S$ & $Z O$ & $N S$ & $N S$ & $N M$ & $N M$ & $N B$ \\
$P B$ & $Z O$ & $Z O$ & $N S$ & $N M$ & $N M$ & $N B$ & $N B$ \\
\hline
\end{tabular}

Table 2. Fuzzy control rules of $\Delta K_{I}$.

\begin{tabular}{c|ccccccc}
\hline EC & $N B$ & $N M$ & $N S$ & $Z O$ & $P S$ & $P M$ & $P B$ \\
\hline$N B$ & $N B$ & $N B$ & $N M$ & $N M$ & $N S$ & $Z O$ & $Z O$ \\
$N M$ & $N B$ & $N M$ & $N M$ & $N S$ & $N S$ & $Z O$ & $P M$ \\
$N S$ & $N B$ & $N M$ & $N S$ & $N S$ & $Z O$ & $P S$ & $P M$ \\
$Z O$ & $N M$ & $N M$ & $N S$ & $Z O$ & $P S$ & $P M$ & $P M$ \\
$P S$ & $N M$ & $N S$ & $Z O$ & $P S$ & $P S$ & $P M$ & $P B$ \\
$P M$ & $N S$ & $Z O$ & $P S$ & $P S$ & $P M$ & $P B$ & $P B$ \\
$P B$ & $Z O$ & $Z O$ & $P S$ & $P M$ & $P M$ & $P B$ & $P B$ \\
\hline
\end{tabular}

Table 3. Fuzzy control rules of $\Delta K_{D}$.

\begin{tabular}{c|ccccccc}
\hline $\mathrm{EC}$ & $N B$ & $N M$ & $N S$ & $Z O$ & $P S$ & $P M$ & $P B$ \\
\hline$N B$ & $P S$ & $N S$ & $N B$ & $N B$ & $N B$ & $N M$ & $P S$ \\
$N M$ & $P S$ & $N S$ & $N B$ & $N M$ & $N M$ & $N S$ & $P S$ \\
$N S$ & $Z O$ & $N S$ & $N M$ & $N M$ & $N S$ & $N S$ & $Z O$ \\
$Z O$ & $Z O$ & $N S$ & $N S$ & $N S$ & $N S$ & $N S$ & $Z O$ \\
$P S$ & $Z O$ & $Z O$ & $Z O$ & $Z O$ & $Z O$ & $Z O$ & $Z O$ \\
$P M$ & $P B$ & $P S$ & $P S$ & $P S$ & $P S$ & $P S$ & $P B$ \\
$P B$ & $P B$ & $P M$ & $P M$ & $P M$ & $P S$ & $P S$ & $P B$ \\
\hline
\end{tabular}

Finally, the Simulink model of the fuzzy PID controller is shown in Figure 2.

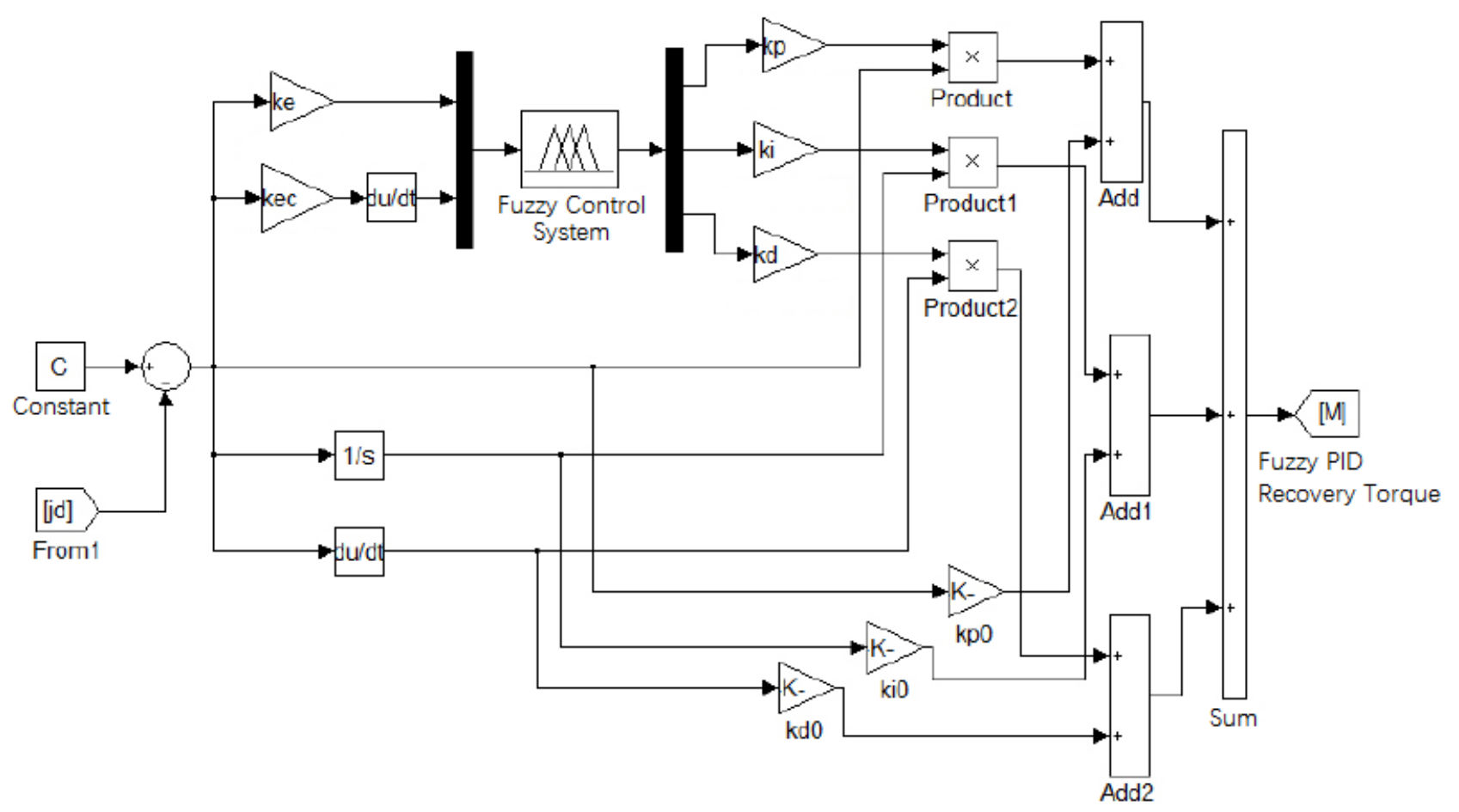

Figure 2. Simulink model of Fuzzy PID controller.

The two level Simulink control block diagrams are given below. Figure 3 shows the active swing bridge adjustment control algorithm, which can automatically tune the output torque by the fuzzy PID control. When the vehicle state detection module detects the vehicle is under the first stage instability risk, this controller will be triggered and provides a recovery torque to the swing bridge. Figure 4 shows the active braking control algorithm, which is based on switch control. When the vehicle state detection module detects the vehicle is under the second stage instability risk, this controller will be 
triggered and output a braking force to the brake pedal. Their work processes will be introduced in Section 4.

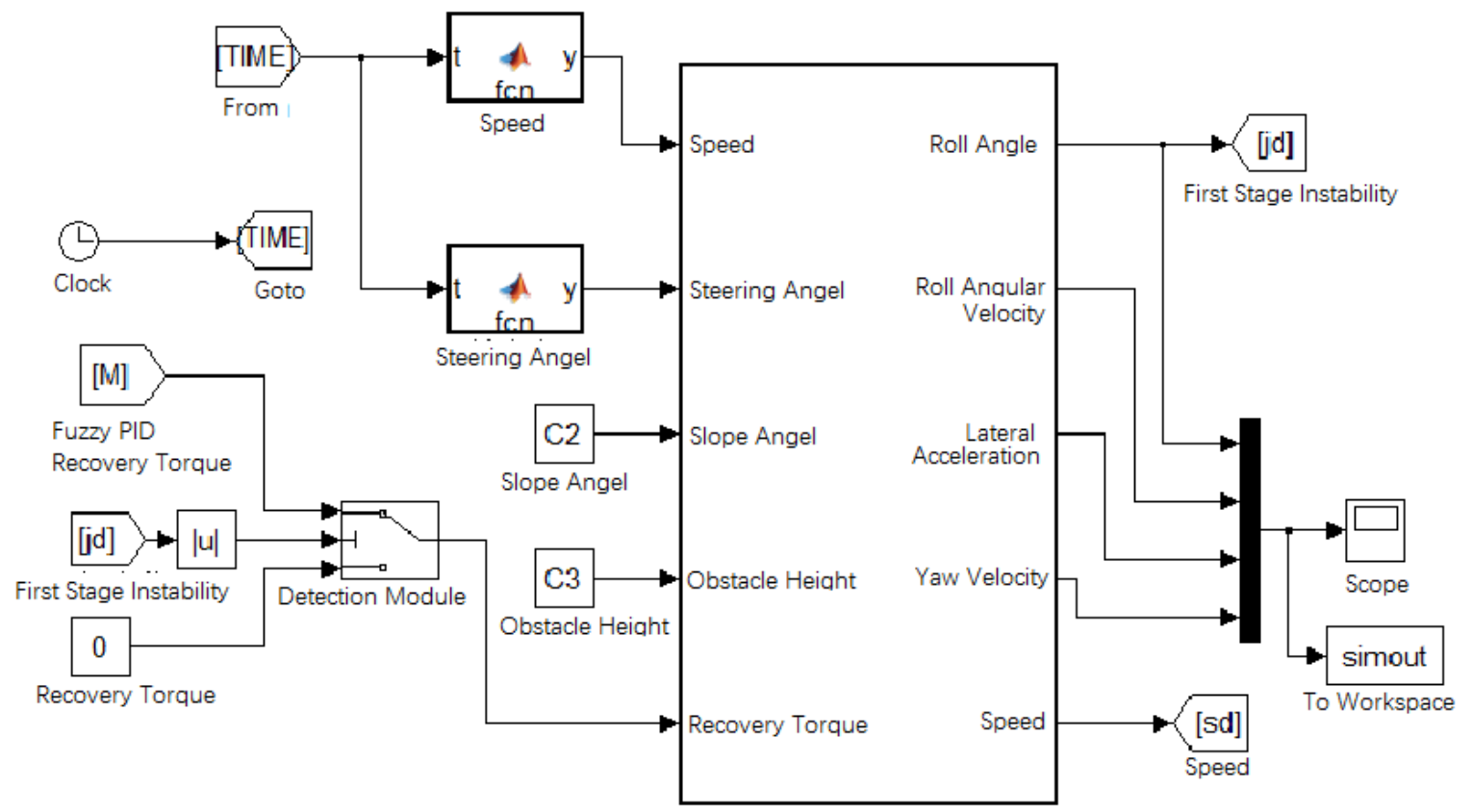

Figure 3. Active swing bridge adjustment control.

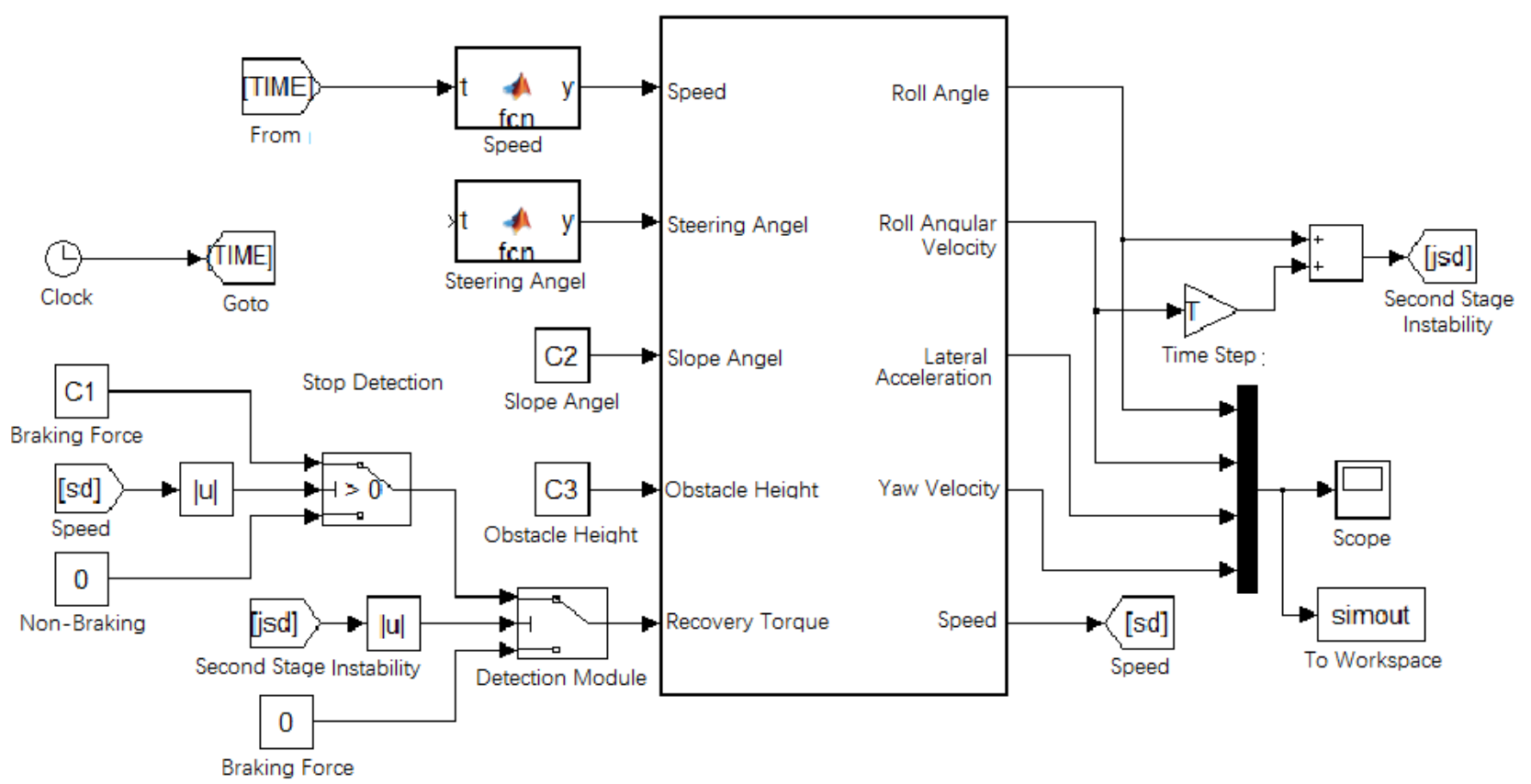

Figure 4. Active braking control.

\section{Multi-body Dynamics Modelling}

The multi-body dynamics model of a ZL50 articulated wheel loader is built by commercial software RecurDyn. This model consists of a front body, a rear body, and a rear axle. The front and rear bodies are linked together by a hydraulic articulated steering system; the rear body and rear axle are linked together by a swing bridge which makes them own relatively independent roll motion. For the tire, FIALA tire model provided by RecurDyn is used. Finally, the road and slope are modelled by Ground module in RecurDyn. After building all rigid models, tire model and road model, the constraints and drive forces between these components are added to the MBD model. The final MBD model is shown in Figure 5. 


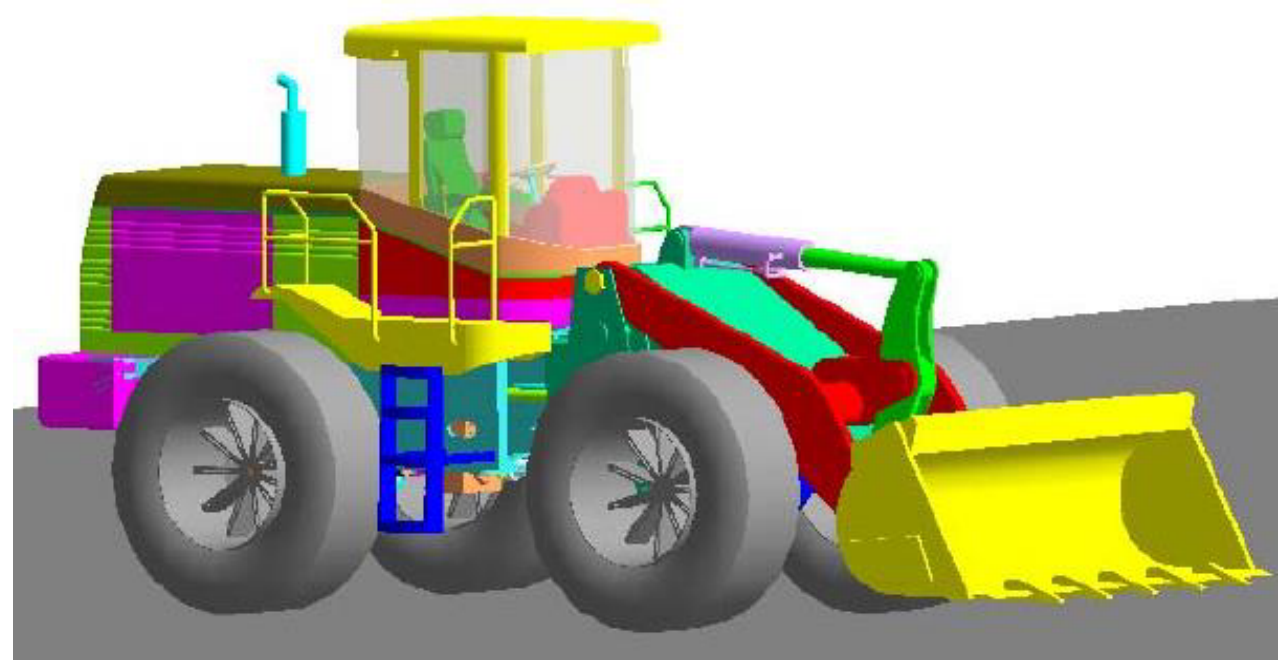

Figure 5. Multi-body dynamics model of a ZL50 wheel loader.

\section{Simulation Setup}

In order to verify the active anti-rollover control algorithm and analyse its effect during the first and second stage instability, a co-simulation was conducted based on the MBD model and the active anti-rollover control model via RecurDyn/CoLink.

Before co-simulating the MBD model and the control system, the input variables (PIN) output variables (POUT) were set up as follows:

PIN: Swing Bridge Recovery Torque, Braking Force;
POUT: $X$-axle speed, $Y$-axle speed, Yaw Velocity, $X$ axle acceleration, $Y$-axle acceleration, Roll Angular Velocity, Roll Angle, Lateral Angular Velocity, etc.

What's more, the driving speed and steering angle were set as constant into the model. Note that the driving speed is in the relative local coordinate system, which is calculated from $X$-axle speed, $Y$-axle speed and Yaw Velocity, and the lateral acceleration is also obtained by $X$-axle acceleration, $Y$-axle acceleration, Roll Angular Velocity, Roll Angle, and Lateral Angular Velocity. The final co-simulation model is shown in Figure 6.

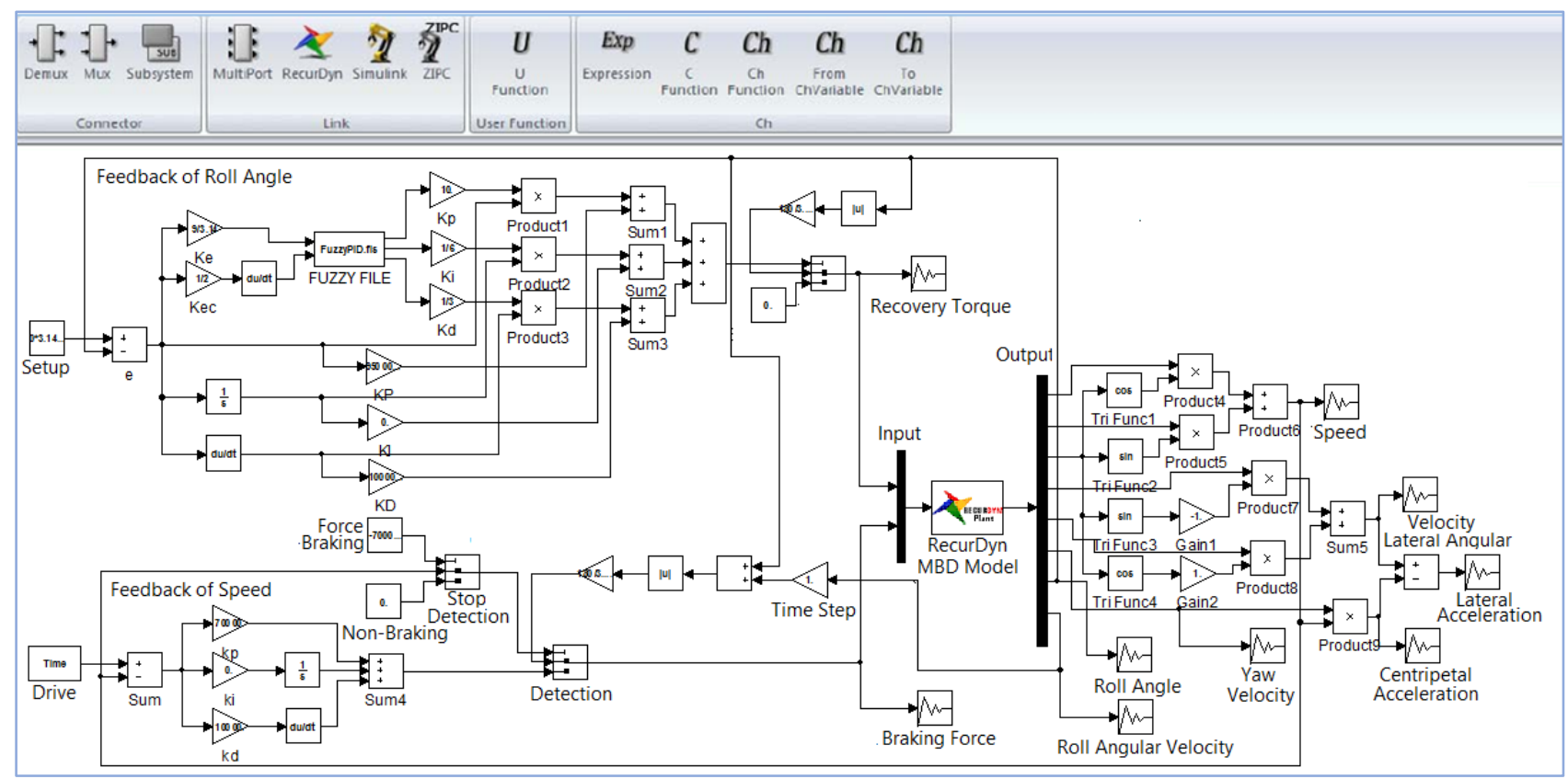

Figure 6. Co-simulation model.

\section{Simulation Results}

There are three different typical rollover situations for the wheel loader: tripped rollover, high speed steering rollover, and slope rollover. In order to verify the first and second instability anti-rollover control algorithm, we chose high speed steering rollover to conduct the simulation and analyse, which can cause rollover by adjusting the driving speed and steering angle. Figure 7 shows the rollover process by increasing the driving speed of the vehicle, Figure 7(a) shows the first instability (one front wheel leaves the ground) and Figure 
7(b) shows the second instability (two wheel in one side of the vehicle all leave the ground).

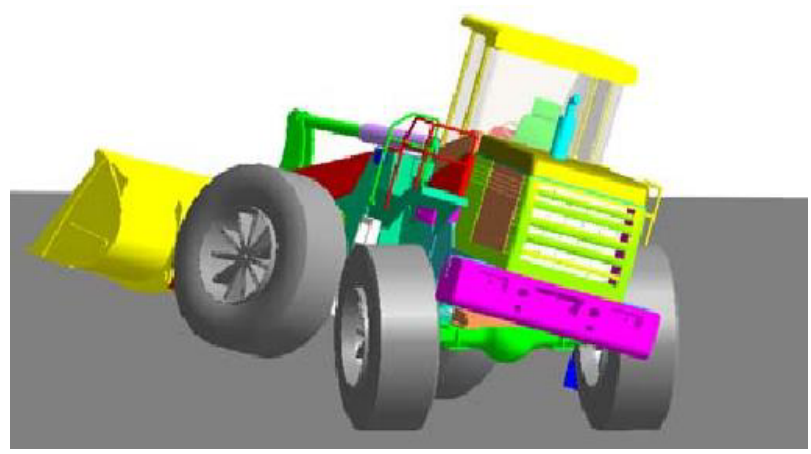

(a) First stage instability

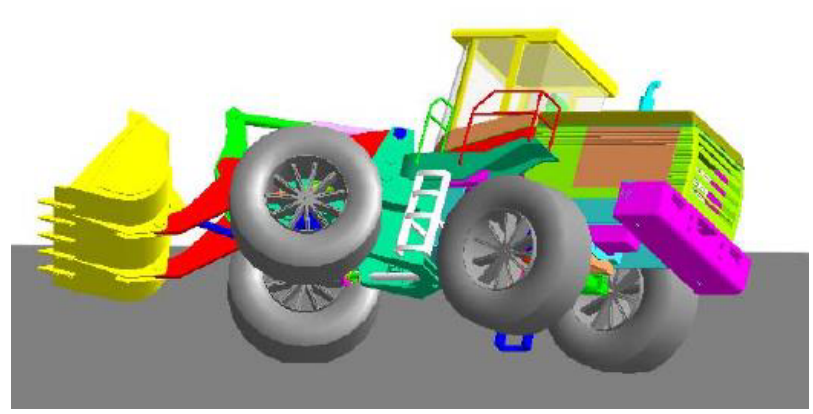

(b) Second stage instability

Figure 7. High speed steering rollover process of wheel loader.

When the wheel loader runs fast on straight road with a sudden steering, the first instability occurs when the steering angle reaches 30 degrees and the driving speed reaches $6 \mathrm{~m} / \mathrm{s}$. If the control system detects this situation, it will apply a recovery torque on the swing bridge. As shown in Figure 8 (a), a sudden steering angle is applied after 2 s straight drive: without control, the roll angle increases sharply and results in the first instability, after 6 $\mathrm{s}$ the whole loader is rollover; when the active control is activated, before the first instability occurs, as shown in Figure 8 (c), a swing bridge recovery torque works and forces the loader to stay stable.

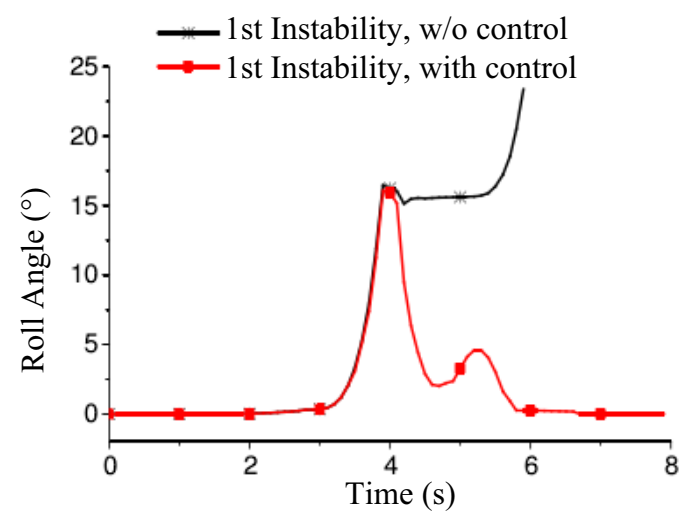

(a) Roll Angle

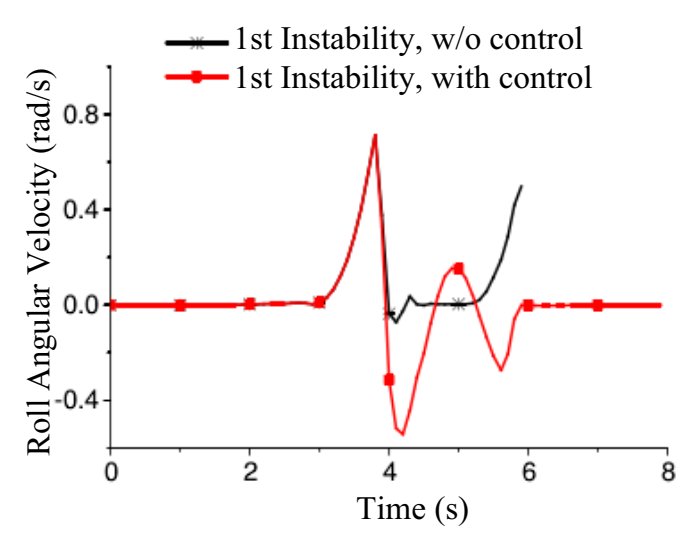

(b) Roll Angular Velocity

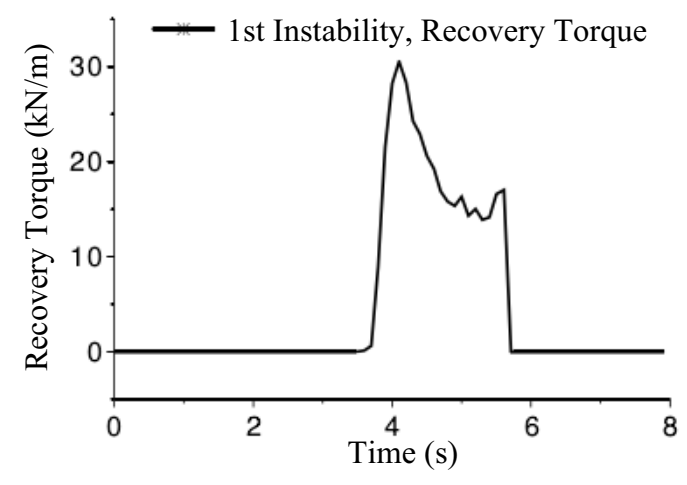

(c) Recovery Torque

Figure 8. The first stage instability control.

Similarly, when the driving speed continues to increase and reaches $8 \mathrm{~m} / \mathrm{s}$, the vehicle reaches to the limit of the second instability, then the control system applies a braking force and reduces the rollover possibility until the vehicle stops. Figure 9 (a) and (b) show the comparison between with and without active control when the vehicle is under the second instability. As shown in Figure 9 (a), without control, the roll angle increases dramatically after $4 \mathrm{~s}$ and finally rollover accident happens. When the active control is activated, the first instability also occurs at $4.4 \mathrm{~s}$, and then the vehicle roll angle has a certain degree of reduction dues to the recovery torque, but it could not eliminate the rollover trend, and the second instability still occurs at $6.2 \mathrm{~s}$. Finally, the active braking force is applied to reduce the roll angle and the vehicle recovers to safety condition finally. 


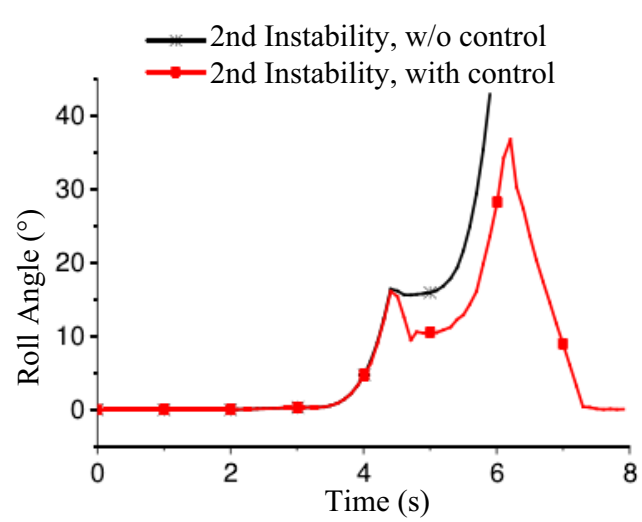

(a) Roll Angle

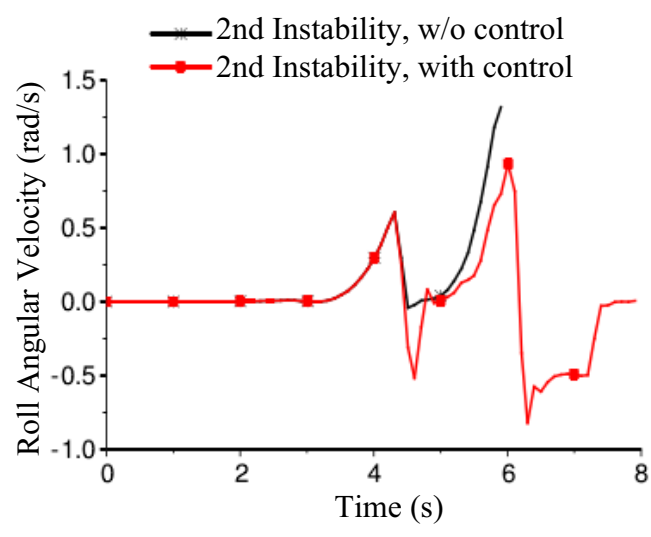

(b) Roll Angular Velocity

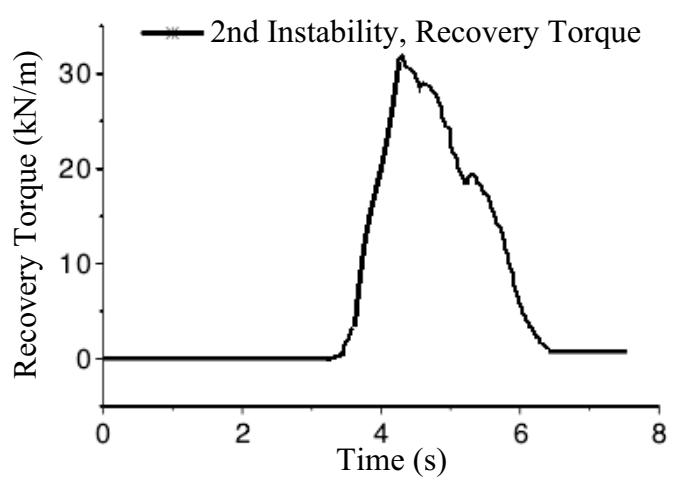

(c) Recovery Torque

Figure 9. The second stage instability control.

\section{Conclusions}

Articulated off-road vehicles are widely used in engineering construction and agricultural production, but most of them are suffered a high possibility of rollover. This paper took advantages from both fuzzy and PID control and developed an active anti-rollover control system. This controller consists two level control, which target to two different instability stages: 1) the active swing bridge adjustment control algorithm for the first stage instability; and 2) the active braking control algorithm for the second stage instability. They work together to prevent the articulated wheel loader from rollover accident.

The multi-body dynamics model of the wheel loader is built by commercial software RecurDyn, and then the MBD model and controller model are co-simulated under the same solver in RecurDyn/CoLink. The co-simulation results show that, during the high speed steering rollover process, the active swing bridge control system works well to prevent rollover when the steering angle reaches 30 degrees and the driving speed reaches $6 \mathrm{~m} / \mathrm{s}$. However, when the driving speed continues to increase and reaches $8 \mathrm{~m} / \mathrm{s}$, only the first level control is not enough to prevent rollover, and the active braking control is needed to reduce the accident possibility.

\section{Acknowledgements}

This study was supported by the National Natural Science Foundation of China (Grant No. 51175216).

\section{References}

1. G.M. Saltzman, M.H. Belzer. Nat. Inst. for Occu. Saf. and Hea. (2007).

2. M. Iida, H. Nakashima, H. Tomiyama. Comp. and Elec. in Agri., 76(2): 277-283 (2011).

3. ISO 3471, Earth-Moving Machinery-Roll-Over Protective Structures-Laboratory Tests and Performance Requirements, (2008).

4. Y.X. Zhang, G.Q. Wang, C. Chen, J.N. Qu. Eng. Veh, 6(42):56-63 (2011).

5. N.L. Azad, J. Mc Phee, A. Khajepour. SAE Paper, No.2005-01-3597 (2005).

6. S.J. Reynolds, W. Groves. Amer. J. of Prev. Med., 18(4S): 63-69 (2000).

7. Y.X. Zhang. Changchun: Jilin University, 2012.

8. D.J.M. Sampson, G. Mckevitt, D. Cebon. Veh. Sys. Dyn., (33): 704-715 (2000).

9. P. Gaspar, I. Szaszi, J. Bokor. Cont. Eng. Pra., 13(6): 699-711 (2005).

10. M.M. Islam. Ontario: University of Ontario Institute of Technology (2013).

11. N. Daher. Cont. Eng. Prac. (45): 46-5348(2015).

12. Y.T. Juang, Y.T. Chang, C.P. Huang. Info. Sci., 178(5): 1325-1333 (2008).

13. J. Carvajal, G.R. Chen, H. Ogmen. Info. Sci., 123(3): 249-270 (2000). 